\title{
Benefits of Cooperation in Transnational Water-Energy Systems
}

\author{
Luchner, Jakob; Riegels, Niels D.; Bauer-Gottwein, Peter
}

Published in:

Journal of Water Resources Planning and Management

Link to article, DOI:

10.1061/(ASCE)WR.1943-5452.0001047

Publication date:

2019

Document Version

Peer reviewed version

Link back to DTU Orbit

Citation (APA):

Luchner, J., Riegels, N. D., \& Bauer-Gottwein, P. (2019). Benefits of Cooperation in Transnational Water-Energy Systems. Journal of Water Resources Planning and Management, 145(5).

https://doi.org/10.1061/(ASCE)WR.1943-5452.0001047

\section{General rights}

Copyright and moral rights for the publications made accessible in the public portal are retained by the authors and/or other copyright owners and it is a condition of accessing publications that users recognise and abide by the legal requirements associated with these rights.

- Users may download and print one copy of any publication from the public portal for the purpose of private study or research.

- You may not further distribute the material or use it for any profit-making activity or commercial gain

- You may freely distribute the URL identifying the publication in the public portal

If you believe that this document breaches copyright please contact us providing details, and we will remove access to the work immediately and investigate your claim. 


\section{Benefits of cooperation in trans-national water- 2 energy systems}

3 Jakob Luchner ${ }^{1}$; Niels D. Riegels, Ph.D. ${ }^{2}$; Peter Bauer-Gottwein, Ph.D. ${ }^{3}$

$4 \quad{ }^{1}$ Department of Environmental Engineering, Technical University of Denmark, Anker Engelunds

5 Vej 1, 2800 Kgs. Lyngby, Denmark. (corresponding author). E-mail: jalu@ dhigroup.com.

$6 \quad{ }^{2}$ Senior Water Resources Engineer, Water Resources Department, DHI, Agern Allé 5, 2970 7 Hørsholm, Denmark. E-mail: ndr@ dhigroup.com.

$8{ }^{3}$ Professor, Department of Environmental Engineering, Technical University of Denmark, Anker 9 Engelunds Vej 1, 2800 Kgs. Lyngby, Denmark. E-mail: pbau @env.dtu.dk.

10 Abstract: Cooperation in international river basins is often challenged by upstream-downstream

11 conflicts over water allocation. In many cases, water allocation is linked to the energy sector

12 through hydropower. In this study, the water value method was used to simulate reservoir

13 operations in an international basin given different assumptions about national priorities and

14 regional energy cooperation. Benefits in the water sector and the power sector were compared

15 considering both cooperative and non-cooperative behavior by national players. The approach is

16 demonstrated for a semi-arid international river basin characterized by conflict between upstream

17 hydropower production and downstream irrigated agriculture. A scenario assuming regional

18 cooperation in the power sector came closest to the multi-sectoral basin cooperation benchmark

19 and produced fewer national costs than scenarios assuming non-cooperative behavior. The results

20 emphasize that power and water resources allocation should be viewed jointly in international river

21 basins where upstream hydropower operations can impact downstream irrigation supplies.

22 International cooperation in the power sector may ease upstream-downstream conflicts in these

23 cases.

\footnotetext{
${ }^{1}$ Now: Junior Water Resources Engineer, Water Resources Department, DHI, Agern Allé 5, 2970 Hørsholm, Denmark.
} 


\section{Introduction}

25 There are more than 260 identified international river basins world-wide which affect about $40 \%$

26 of the world's population (Wolf 1998). In international river basins, competition between upstream

27 and downstream countries may have significant economic impacts. The conflict is often between

28 irrigation and hydropower, particularly when a seasonal mismatch exists between peak demands.

29 Prominent examples of upstream-downstream disputes on water allocation in international river

30 basins are the Nile basin and the Aral Sea basin. Existing disputes between riparian countries in

31 international river basins are further challenged by world population growth and climate change.

32 Sadoff and Grey (2002) suggested that water conflicts in international river basins could be eased

33 by changing the perspective from sharing water itself to sharing the benefits from the use of water.

34 The main argument is that focusing on the benefits from the use of water transforms the zero-sum

35 game related to sharing water itself into a positive-sum game where all stakeholders could gain

36 from cooperation. Such a 'win-win' situation implies the assumption that the river basin as a whole

37 benefits from cooperation and that the benefits are distributed fairly (Dombrowsky 2009). Both

38 assumptions were addressed in recent research. Arjoon et al. (2014), Tilmant and Kinzelbach

39 (2012) and Whittington et al. (2005) assessed the value of cooperation in international river basins

40 and found that there are significant gains from basin-wide cooperation. The equity issue of sharing

41 benefits from cooperation has been addressed by game theory (Teasley and McKinney 2011; Wu

42 and Whittington 2006) and an approach based on a stakeholder vision of fairness (Arjoon et al.

43 2016). Despite the apparent benefits, cooperation in international basins can often be obstructed

44 by national and single-sector interests, who may be reluctant to make long-term commitments to

45 coordinate water use because of uncertainty about future water supply and demand as well as high

46 transaction costs ( Wu and Whittington 2006). 
47 In the last decades, hydro-economic models have been applied in various contexts to investigate

48 the economic efficiency of water allocation plans. These models normally consider simple mass

49 balance schemes of the river network and may use optimization according to economic criteria to

50 establish an efficiency benchmark or simulate the economic behavior of water users (Booker et al.

51 2012; Harou et al. 2009). In a typical formulation, hydrologic, agronomic and economic

52 information are used to maximize (minimize) the benefits (costs) related to different water uses

53 such as irrigation, hydropower, and industrial and domestic water use. Recent surveys of hydro-

54 economic models and their applications can be found in Bauer-Gottwein et al. (2016), Booker et

55 al. (2012), Harou et al. (2009) and Momblanch et al. (2016).

56 In river basins where hydropower plays an important role for the regional economy, the benefit of

57 water use for hydropower has to be included in the formulation of a hydro-economic model. A

58 common approach is to estimate the hydropower benefit based on constant or monthly-varying

59 exogenous electricity prices (Anghileri et al. 2013; Arjoon et al. 2014; Tilmant and Kelman 2007).

60 However, this approach might misrepresent the value of hydropower in the energy supply mix,

61 particularly when demands and alternative supply costs are varying. Pereira-Cardenal et al. (2015)

62 demonstrated the advantages of estimating hydropower values as an output from the interaction

63 between hydro-economic and power system models rather than an input to the hydro-economic

64 model.

65 This paper describes the implementation of a hydro-economic modeling approach to estimate the

66 benefit of power sector cooperation in international river basins. Power sector cooperation is

67 compared to a multi-sector cooperation benchmark as well to scenarios in which national and

68 sectoral priorities drive water allocation. The hydropower value is determined endogenously. 
69 The proposed methodology was developed for semi-arid international river basins which are

70 characterized by conflicting water use between irrigated agriculture and hydropower in an

71 upstream-downstream configuration. Stochastic dynamic programming (SDP) was applied in

72 combination with the so-called water value method to simulate reservoir operations and water

73 allocation under different cooperation assumptions. The Syr Darya basin (SDRB) in Central Asia

74 was used as a case study.

\section{Material and Methods}

\section{The Syr Darya Basin}

77 The Syr Darya is one of the two main tributaries to the Aral Sea in Central Asia. The basin is

78 characterized by a semi-arid climate and a high dependence on irrigated agriculture. Agriculture

79 represents the largest consumptive water use, while hydropower represents the largest non-

80 consumptive water use in the basin. International water politics between the riparian countries are

81 dominated by the conflict between water use for hydropower in the upstream countries and

82 irrigated agriculture in the downstream countries. The conflict potential in water use for

83 hydropower and irrigated agriculture in an upstream-downstream configuration is not unique to

84 the Syr Darya basin but finds a parallel, for example, in the Nile basin (Wu and Whittington 2006).

85 About $70 \%$ of the river flow originated in the upstream part of the basin in the territory of

86 Kyrgyzstan (Cai 1999). The vast amounts of water combined with high elevation differences in

87 this area create highly favorable conditions for hydropower production. In fact, the biggest

88 reservoir in the basin, Toktogul (storage: $19500 \times 10^{6} \mathrm{~m}^{3}$ ), is located in Kyrgyzstan. Originally,

89 the reservoir was built by the Soviet Union in order to secure water supply to agriculture in 
90 downstream regions. After the disintegration of the Soviet Union, Kyrgyzstan's winter electricity

91 demand increased significantly due to introduction of electrical heating. Today, Kyrgyzstan, which

92 is without significant hydrocarbon resources, is dependent on hydropower from Toktogul and the

93 downstream Naryn Cascade during the winter months.

94 Conversely, irrigated agriculture in Uzbekistan and Kazakhstan depends on releases from

95 Toktogul during the vegetation period (April-October) in dry inflow years. Irrigated agriculture is

96 an important economic activity in both countries. Agriculture (mostly irrigated) contributes $21 \%$

97 of Uzbekistan's gross domestic product (GDP) (The World Bank 2012).

98 The river course, reservoirs and agricultural planning zones defined in this study are illustrated in

99 Fig. 1.

100 Fig. 1. Base Map of the Syr Darya River basin. Agricultural planning zones are introduced to 101 summarize irrigative water use in the respective area. The names of the planning zones indicate 102 the region and the country in which they are located (CHI: Chirchic River, FER: Fergana Valley, 103 NOR: Syr Darya Delta, SYR: Syr Darya Valley, KYR: Kyrgyzstan, TAD: Tajikistan, UZB: 104 Uzbekistan, KAZ: Kazakhstan).

105 In 1992, the seasonal mismatch between upstream and downstream water demand led to the 106 foundation of the Interstate Commission for Water Coordination in Central Asia (ICWC). The 107 commission includes representatives of the five governments of Kazakhstan, Uzbekistan, 108 Tajikistan, Kyrgyzstan and Turkmenistan and is entrusted with interstate water resources 109 management. Several agreements have been made in order to ensure sufficient releases from 110 Toktogul in the vegetation period. Probably, the most important is the "Agreement on the Use of 111 Water and Energy Resources in the Syr Darya Basin" (ICWC 1998) between Kyrgyzstan, 
112 Uzbekistan and Kazakhstan. Tajikistan joined the agreement in 1999. The agreement asks for 113 sufficient releases from Toktogul to satisfy irrigation demands in Uzbekistan and Kazakhstan. In

114 return, Uzbekistan and Kazakhstan should compensate Kyrgyzstan with coal, gas and electricity

115 or their monetary equivalent in the non-vegetation period. Compliance with this agreement and all

116 following ones is jeopardized by the uncertain value of Toktogul's storage (Teasley and McKinney

117 2011): Uzbekistan and Kazakhstan are willing to compensate Kyrgyzstan for releases from

118 Toktogul in the vegetation period but they are not willing to compensate Kyrgyzstan for storing

119 water during wet years to hedge against the risk of low inflow in the following years. Water rights

120 trading is one potential solution discussed by the ICWC and other authorities in the Aral Sea basin

121 to facilitate basin-wide cooperation. Bekchanov et al. (2015) show by means of hydro-economic

122 modeling that water rights trading could increase basin-wide benefits significantly.

123 Besides basin-wide cooperation in the water sector for agricultural use, an opportunity for 124 cooperation in the power sector exists through the Central Asian Power System (CAPS). It is a 125 cluster of national grids, including the grids of Southern Kazakhstan, Uzbekistan, Tajikistan, 126 Kyrgyzstan and Turkmenistan, operating in parallel to the United Energy System of Russia via 127 Kazakhstan (Tomberg 2012). During the Soviet Union, this power system, composed of 83 power 128 plants from Kazakhstan, Uzbekistan, Tajikistan, Kyrgyzstan and Turkmenistan, was run centrally 129 from Tashkent, Uzbekistan. After the disintegration of the Soviet Union, national interests have 130 led to misappropriation of CAPS and it went out of operation in 2009 (Tomberg 2012).

131 For a detailed description of the political development in the region after the disintegration of the 132 Soviet Union, the reader is referred to the following references: Antipova et al. (2002), Cai (1999) 133 and Dinar et al. (2007). 
134 In summary, water and power resources allocations in the basin are tightly linked by hydropower.

135 The dilemma of power supply deficits in Kyrgyzstan and water supply deficits for irrigated 136 agriculture in the downstream countries is the core of the water use conflict in the Syr Darya basin.

\section{Stochastic dynamic programming - water value method}

138 As mentioned previously, bilateral agreements fail because the value of storing water in Toktogul

139 during wet years to hedge against the risk of low inflow in coming years is unknown. Toktogul is

140 the only reservoir in the basin with inter-annual storage capacity. Therefore, this study focuses on

141 the upstream-downstream dispute on the releases from Toktogul for hydropower and irrigated

142 agriculture. Because of the inter-annual management focus, we argue that the basin can be

143 reasonably represented as a one-reservoir system.

144 Stochastic dynamic programming (SDP) in combination with the water value method (see

145 Wolfgang et al., (2009) and references herein) represents a method to derive optimal reservoir

146 operating rules based on the efficient reservoir storage value as function of storage level, month of

147 the year and inflow uncertainty. The value of stored water is determined for a discrete number of

148 reservoir volume segments for each month of the year and inflow scenario (volume segments are

149 denoted by index m). The calculation of water values for each reservoir volume segment is possible

150 with SDP because the algorithm evaluates backward-moving the entire state space. That is the

151 reason why SDP was chosen as optimization method despite its drawbacks due to the curses of

152 dimensionality (see Giuliani et al. (2016)). For reviews on optimization methods for reservoir

153 operation the reader is referred to Castelletti et al. (2008) and Labadie (2004).

154 Reservoir operation is a complex optimization problem because present releases have to be

155 balanced against expected future benefits. These are uncertain due to uncertain future demand and 
156 supply functions, and uncertain future inflows. The uncertainty for each parameter could be

157 described by separate state variables. However, only a limited number of state variables can be

158 solved efficiently with SDP and therefore a choice is required (see Labadie (2004)). The

159 uncertainty of Toktogul's inflow was considered as most important.

160 Similarly, each lateral inflow would have to be a state variable in the SDP optimization in order to

161 include them as stochastic inflows in the model. The lateral inflows were included in the

162 optimization phase as monthly average flows based on time series of the period 1960-1990. This

163 period was chosen because data for all lateral inflows and the inflow to Toktogul were available

164 for this period and it contains a sufficient range of wet, normal and dry inflow years to illustrate

165 the upstream-downstream water allocation conflict. It was verified that the use of average lateral

166 inflows does not significantly affect the resulting reservoir operation for the used model. The

167 optimization model also considered return flows (see Fig. 2: Ret_FER, Ret_MID, Ret_DS),

168 seepage losses from the river network and a minimum inflow requirement to the Northern Aral

169 Sea. Fig. 2 shows the conceptual river network used for the optimization.

170 Fig. 2. Conceptual River Network.

171 The optimization is based on the recursive Bellman Equation (see Equation (2.1)) (Bellman 1957).

172 The algorithm is applied backward-moving in monthly time steps. Each objective is expressed in

173 economic terms and the single objective function is calculated as sum of the monetary values.

174 Consequently, the different objectives are implicitly weighted by their monetary value for society.

175 Benefits from water allocations to agriculture are maximized and costs for power production are

176 minimized over the planning horizon. This yields so-called water value tables for each inflow 
177 scenario. They define an efficient reservoir operating rule as a function of reservoir storage, month

178 of the year and inflow scenario.

179 The inflow to Toktogul is described by a discrete first-order monthly Markov Chain. Five inflow 180 classes are defined based on quantiles of monthly flow records of the period 1911-1998: very dry $181\left(0^{\text {th }}-10^{\text {th }}\right.$ quantile $)$, dry $\left(10^{\text {th }}-30^{\text {th }}\right)$; medium $\left(30^{\text {th }}-70^{\text {th }}\right)$; wet $\left(70^{\text {th }}-90^{\text {th }}\right)$; very wet $\left(90^{\text {th }}-100^{\text {th }}\right)$.

182 Discrete flows, $q_{k, t}$, are defined as mean values of the observed flows falling into the defined 183 classes. Serial correlation is modeled by transition probabilities, $p_{k l}$, which express the conditional 184 probability of moving from inflow scenario $\mathrm{k}$ in time step $\mathrm{t}$ to inflow scenario 1 in time step $\mathrm{t}+1$.

185 The transition probabilities are approximated by the normalized transition frequencies observed in 186 the period 1911-1998. Statistically, the empirically derived transition probabilities approximate 187 the underlying transition probabilities more accurate the longer the observation record. The period 188 1911-1998 was the longest, stationary inflow series to Toktogul available and hence the period 189 chosen to derive the discrete first-order Markov Chain.

190 The state of the system is defined by Toktogul's storage volume, $v_{m, t}$, and the current month's

191 inflow, $q_{k, t}$. The optimal value function, $\mathrm{F}_{t}^{*}\left(v_{m, t}, q_{k, t}\right)$, maximizes in each time step the sum of

192 immediate, $\mathrm{b}_{t}\left(\mathbf{x}_{t}, \mathbf{t p p}_{t}, \mathbf{u s d}_{t}\right)$, and expected future benefits, $\underset{q_{k, t}}{\mathrm{E}}\left[\mathrm{F}_{t+1}^{*}\left(v_{t+1}, q_{t+1}\right)\right]$ :

$$
\mathrm{F}_{t}^{*}\left(v_{m, t}, q_{k, t}\right)=\max _{\mathbf{x}_{t}, \mathbf{t p p}_{t}, \mathbf{u s d}_{t}}\left\{\mathrm{~b}_{t}\left(\mathbf{x}_{t}, \mathbf{t p p}_{t}, \mathbf{u s d}_{t}\right)+\underset{q_{k, t}}{\mathrm{E}}\left[\mathrm{F}_{t+1}^{*}\left(v_{t+1}, q_{t+1}\right)\right]\right\}
$$

194 immediate benefits:

$$
\mathrm{b}_{t}\left(\mathbf{x}_{t}, \mathbf{t p p}_{t}, \mathbf{u s d}_{t}\right)=\mathbf{m} \mathbf{b}_{a g r}^{T} \cdot \mathbf{x}_{t}-\mathbf{c}_{t p p}^{T} \cdot\left(\mathbf{t p p}_{\text {base }, t}+\mathbf{t p p}_{\text {peak }, t}\right)-\mathbf{c}_{u s d}^{T} \cdot\left(\mathbf{u s d}_{b a s e, t}+\mathbf{u s d}_{\text {peak }, t}\right)
$$

196 expected future benefits: 


$$
\underset{q_{k, t}}{\mathrm{E}}\left[\mathrm{F}_{t+1}^{*}\left(v_{m, t+1}, q_{t+1}\right)\right]=\sum_{l} p_{k l} \cdot \mathrm{F}_{t+1}^{*}\left(v_{m, t+1}, q_{l, t+1}\right)
$$

198 where $\mathbf{x}_{t}$ is the vector expressing water allocations to each crop type in each planning zone, $\mathbf{m b}_{\text {agr }}^{T}$

199 represents the corresponding agricultural water value, $\mathbf{t p p}_{t}$ is the vector of thermal power

200 production for all TPPs, $\mathbf{c}_{t p p}$ is the corresponding marginal cost, usd $\mathbf{u}_{t}$ is the unserved power

201 demand volume and $\mathbf{c}_{u s d}$ stands for corresponding curtailment costs (see the following section for

202 more explanations on the variables).

203 Equation (2.1) defines a one-stage optimization problem resulting in optimal releases, water and 204 power allocations in each time step. The one-stage optimization problem is a linear program (LP) 205 that was solved using the cplexlp solver by $\mathrm{IBM}^{\circledR}$. The main constraints are the water balance at 206 Toktogul, limits to irrigation water withdrawals, water availability at the irrigation sites, limits to 207 releases from Toktogul, limits to thermal power production, limits to the defined unserved power 208 demand segments and the satisfaction of observed power demand during base and peak hours. The 209 expected future benefit function is approximated by a piece-wise linear function in order to avoid 210 discretizing the decision variables. This approximation is also introduced as constraints to the 211 optimization (see Equation (2.4)).

$$
\underset{q_{k, t}}{\mathrm{E}}\left[\mathrm{F}_{t+1}^{*}\left(v_{t+1}, q_{t+1}\right)\right] \approx-\pi_{m} \cdot\left(v_{m, t+1}-v_{t+1}\right)+\underset{q_{k, t}}{\mathrm{E}}\left[\mathrm{F}_{t+1}^{*}\left(v_{m, t+1}, q_{t+1}\right)\right] \quad \text { for } \mathrm{m}=1,2, \ldots, \mathrm{M}-1
$$

$$
\pi_{m}=\frac{\underset{q_{k, t}}{\mathrm{E}}\left[\mathrm{F}_{t+1}^{*}\left(v_{m, t+1}, q_{t+1}\right)\right]-\underset{q_{k, t}}{\mathrm{E}}\left[\mathrm{F}_{t+1}^{*}\left(v_{m, t+1}, q_{t+1}\right)\right]}{v_{m+1, t+1}-v_{m, t+1}}
$$

213 where $\mathrm{m}$ is the index for the discretized storage volumes and $\mathrm{M}$ is the index indicating the 214 maximum storage volume. 
215 Water values, WV [USD/m³], for each reservoir level correspond to the shadow prices of the water

216 balance constraint at Toktogul (see Equation (2.5)).

$$
W V_{t}=\frac{\partial \mathrm{F}_{t}^{*}}{\partial v} \approx \frac{\Delta \mathrm{F}_{t}^{*}}{\Delta v}
$$

218 In the presented study, the storage discretization is chosen to ensure a good approximation of the 219 derivative. Nevertheless, the authors acknowledge that state-of-the-art linear programming solvers

220 provide shadow prices as output variables and hence the water values could be obtained in each

221 step directly from the solver. The algorithm is run for several years until the water values are no 222 longer dependent on the end point condition.

223 System operation is simulated forward-moving using historical inflow time series for the period

224 1960-1990 instead of average lateral inflows used during the optimization. Based on the observed

225 inflow and storage volume in time step t, solving the linear program in Equation (2.1) results for 226 each time step in releases, water and power allocations that maximize immediate and expected 227 future benefits. The expected future benefit function is estimated from the water value tables. The 228 slopes of the expected future benefit function are given by the weighted average of $W V_{t+1}$ weighted 229 with the respective transition probabilities.

\section{Hydro-Economic Input Data}

231 Unless otherwise noted, all input data used in this study are from data collection executed during 232 the Aral Sea Basin Economic Allocation Model (BEAM) project conducted by the World Bank in 233 2013. The data were obtained by personal communication with Dr. Benoit Blarel of the World 234 Bank on 13.11.2017. 


\section{Hydrological input data}

236 The river runoff pattern in the SDRB is correlated to snow accumulation during the previous winter 237 season (October-March) and the extent of glaciers in the Tien Shan mountains (Oberhänsli et al. 238 2011). As a consequence, the river runoff is highly seasonal. About 70-80\% of the total annual 239 river flow occurs in the summer season (April-September) (see Fig. 3).

240 Fig. 3. Monthly average inflows to Toktogul of the period $1911-1998$.

\section{Agricultural input data}

242 Fifteen crop types are considered in the model. Cotton and wheat are the most frequently grown 243 crops in the basin. Data for crop evapotranspiration, effective rainfall, crop area, leaching volumes, 244 and seepage losses from channels and at field level are available. Seepage losses from channels 245 transporting the river water to the agricultural site and at field level are significant in the basin 246 (both approximately 30\% according to stakeholder workshops conducted during the BEAM 247 project and Bekchanov et al. (2016)). They are used as proxy for the basin efficiency which defines

248 the ratio between water diverted from the river and water that actually reaches the crop. Monthly 249 irrigation water requirements for each crop type in each planning zone are calculated with these 250 input data. It is assumed that the crop area distribution in the basin is constant over the planning 251 horizon.

252 The total average annual river discharge is about $40 \%$ less than total annual irrigation water 253 requirement. This underlines the water scarcity in the basin. Uzbekistan has by far the highest 254 irrigation water demand; especially for cotton and wheat. The Uzbek annual irrigation water 255 demand is more than 3.5 times larger than the second highest demand of Kazakhstan. 
256 Detailed demand functions for agricultural users in the Syr Darya basin are not available and

257 therefore constant marginal benefits are assumed. Consequently, average and marginal water

258 values are identical. Marginal agricultural water values are calculated with the residual imputation

259 method based on the production exhaustion theorem (Young and Loomis 2014). Input costs for

260 labor, seeds, fertilizers, pesticides and capital (excluding the irrigation system) are considered.

261 When comparing benefits derived from water allocations to competing uses, it is important to

262 compare at-source values instead of at-site values. At-site values are usually larger than at-source

263 values because they value the water which arrives at the user site neglecting losses and conveyance

264 costs. Conveyance costs could not be included due to data deficiencies but losses occurring on the

265 way from the river to the crop were included. Fig. 4 lists the resulting estimates of agricultural at-

266 source water values. In the optimization model, it is assumed that these water values are constant

267 throughout the growing season even though the authors are aware that agricultural water values

268 depend on the crop yield - water supply relationship. However, it is argued that this assumption

269 does not significantly affect the comparative valuation of different cooperation scenarios and

270 reduces the complexity of the SDP setup.

271 Fig. 4. Estimated agricultural at-source water values, (USD/m3), for each crop type and planning

272 zone in the Syr Darya basin (alf: alfalfa, cot: cotton, tmt: tomato, wht: wheat, tgr: table grapes,

273 shv: cucumber, ric: rice, pot: potato, sbt: sugar beet, stf: stone fruits, mln: melon, mng: mango,

274 mzf: maize for fodder, mzg: maize for grain). It should be noted that cotton is among the low value 275 crops.

\section{Power system model}

277 The power system of Uzbekistan, Kyrgyzstan and a hypothetical reestablished joint power system

278 between the two is included in the optimization model in order to evaluate the potential impact of 
279 power systems on international river basin cooperation. Approximately $88 \%$ of Uzbekistan's 280 power supply is based on thermal power production (World Energy Council 2007). The Uzbek 281 power system is modeled with 10 thermal power plants (TPP). The Kyrgyz power system is 282 assumed to be composed of one TPP and hydropower from Toktogul and the Naryn Cascade. 90\% 283 of Kyrgyz power supply is based on hydropower of which $97 \%$ are concentrated in the Naryn 284 Cascade (Antipova et al. 2002).

285 The power system model is set up as simple as possible and as complex as needed to serve the 286 purpose. A merit order approach (Wangsteen 2007) is chosen which assumes that producers have 287 constant marginal costs and to satisfy the power demand, production is scheduled from cheapest 288 to most expensive producer. Variable efficiency rates, transmission and security constraints, and 289 costs such as start-up costs are neglected.

290 An elastic demand function is used to model cost efficient allocation of the power resources in 291 Uzbekistan and Kyrgyzstan. For both countries, an elastic demand function is estimated based on 292 observed demand (see Fig. 5), the electricity tariff and price elasticity. Electricity tariffs are found 293 to be 52.5 USD/MWh and 25.2 USD/MWh in Uzbekistan and Kyrgyzstan, respectively. The price 294 elasticity is assumed to equal -0.2 in Uzbekistan and -0.15 in Kyrgyzstan. For linearization 295 purposes, the demand function is divided into 5\% segments of the observed demand. Each segment 296 was associated with a constant willingness to pay.

297 Fig. 5. Observed monthly power demand in Uzbekistan and Kyrgyzstan during base and peak 298 hours, (GWh/month).

299 In the optimization, the estimated power demand function is implemented as curtailment source 300 with a marginal cost corresponding to the willingness to pay for the respective power segment. In 
301 other words, the observed power demand can be satisfied by power production and 5\% curtailment

302 increments at a certain cost. Demand satisfaction is considered separately for base and peak

303 demand hours in one month. If monthly demand was simply averaged, parts of the supply function

304 needed during peak demand hours would be neglected which might influence the hydropower

305 value and reservoir operation significantly. In Kyrgyzstan, power demands peak in the winter

306 months due to climate. Power demand in Uzbekistan peaks during summer months because of

307 electricity requirements for the extensive irrigation system.

\section{Hydropower}

309 From the hydropower perspective, the potential yield of Toktogul and Naryn cascade combined is

310 almost 3 times higher than the next highest potential yield at the Chirchik reservoir (Toktogul and

311 Naryn Cascade: $889 \mathrm{MWh} / 10^{6} \mathrm{~m}^{3}$; Chirchik: $322 \mathrm{MWh} / 10^{6} \mathrm{~m}^{3}$ ). These figures demonstrate that

312 the joint system of Toktogul and Naryn Cascade dominates the Syr Darya basin from the storage

313 and hydropower perspective.

314 For monthly reservoir operation, the storage volume of the Naryn Cascade is negligible compared

315 to releases from Toktogul. Thus, it is assumed that the Naryn Cascade always produces

316 hydropower at maximum head. A constant power yield is assumed for Toktogul and Naryn

317 Cascade combined ( $y_{h p}=860 \mathrm{MWh} / 10^{6} \mathrm{~m}^{3}$ ) in order to reduce complexity of the SDP setup. It

318 corresponds to the medium storage volume of Toktogul, $1250010^{6} \mathrm{~m}^{3}$. The error due to this

319 assumption should be reasonably small because the power yield for Toktogul and Naryn Cascade

320 combined varies only by $17 \%$ over the storage range of Toktogul. At the chosen yield the flow

321 capacity of the Naryn Cascade is the binding flow constraint and thus it is used as maximum release

322 volume for the combined system. 
323 Hydropower production costs are negligible compared to thermal power production and thus

324 hydropower operational costs are assumed to be zero.

\section{Experiment Setting}

326 The simulation approach to demonstrate the impact of collaboration in the power sector and the

327 agricultural sector on international river basin cooperation can be summarized in two steps:

1. Efficient reservoir operating rules (water value tables) for Toktogul are derived using SDP in combination with the water value method.

2. Based on the water value tables, optimal reservoir releases, water allocations, power allocations and related benefits are simulated and compared.

332 In six different cooperation scenarios, Toktogul releases and water allocations are optimized either

333 on the national or the basin scale. Three different operating objectives are considered: (1) benefits

334 in the agricultural sector only (SSAgr) (see Equations (2.9)), (2) costs in the power sector only

335 (SSPower) (see Equations (2.7) and (2.8)) and (3) difference between benefits in the agricultural

336 sector and costs in the power sector (MS) (see Equations (2.2) and (2.6)). Hence, scenario specific

337 steady-state water value tables are determined. These are used to simulate optimal reservoir

338 releases, water allocations, power allocations and corresponding benefits for the different

339 scenarios. The main characteristics of the scenarios are summarized in Table $\mathbf{1}$ and the following

340 sections. The performance of the different scenarios is evaluated based on the cumulative

341 difference between basin-wide benefits in the agricultural sector and costs in the power sector over 342 the simulation period. 


\section{Scenario A: Basin_MS}

344 The basin-multi-sector scenario optimizes the operation of Toktogul to maximize the difference

345 between basin-wide agricultural benefits and power generation costs for a reestablished power grid 346 between Kyrgyzstan and Uzbekistan (see Equation (2.2)). This implies that monthly power

347 demand of Kyrgyzstan and Uzbekistan is summed and can be satisfied with power production from 348 both countries.

349 The basin_MS scenario represents a theoretical benchmark for multi-sector, basin-wide 350 cooperation in the Syr Darya basin.

\section{Scenario D: National_MS}

352 Toktogul releases are optimized to maximize agricultural benefits and to minimize power 353 generation costs in Kyrgyzstan. Water allocation to downstream agricultural sites are determined 354 sequentially with linear programs (LPs, see Equation (2.1) considering only immediate, national 355 agricultural benefits) given the remaining water availability after Kyrgyzstan has implemented 356 unilaterally optimal reservoir release decisions. The Kyrgyz and the Uzbek power system are 357 considered separately. Consequently, the power generation in Uzbekistan is modeled with a linear 358 program which minimizes generation costs (see Equation (2.1) considering only immediate, 359 national power generation costs). Equation (2.6) shows the corresponding objective function.

$\mathrm{b}_{t}=\mathbf{m} \mathbf{b}_{K Y R, a g r}^{T} \cdot \mathbf{x}_{K Y R, a g r, t}-\mathbf{c}_{K Y R, t p p}^{T} \cdot\left(\mathbf{t p p}_{K Y R, b a s e, t}+\mathbf{t p p}_{K Y R, p e a k, t}\right)-\mathbf{c}_{\text {usd }}^{T} \cdot\left(\mathbf{u s d}_{K Y R, b a s e, t}+\mathbf{u s d}_{K Y R, p e a k, t}\right)$

361 The national_MS scenario stands for national appropriation of the water resources and the case 362 that Kyrgyzstan optimizes Toktogul for the agricultural and the power sector. 


\section{Scenario B: Basin_SSPower}

364 A reestablished power grid between Kyrgyzstan and Uzbekistan is considered which implies that

365 monthly power demand of both countries can be satisfied with power resources from both 366 countries. This hypothetically shared power grid is essentially the same as a regional power 367 market. The objective function only contained power generation costs (see Equation (2.7)). Given 368 optimal reservoir release decisions with respect to the joint power system, water allocation to 369 agriculture in each time step is determined sequentially in each country with LPs (see Equation 370 (2.1) considering only immediate, national agricultural benefits).

$$
\mathrm{b}_{t}=-\mathbf{c}_{t p p}^{T} \cdot\left(\mathbf{t p p}_{\text {base }, t}+\mathbf{t p p}_{\text {peak }, t}\right)-\mathbf{c}_{\text {usd }}^{T} \cdot\left(\mathbf{u s d}_{\text {base }, t}+\mathbf{u s d}_{\text {peak }, t}\right)
$$

372 The basin_SSPower scenario is introduced to evaluate the impact of cooperation in the power 373 sector on water resources allocation in the basin.

\section{Scenario E: National_SSPower}

375 For evaluation of cooperation in the power sector the national_SSPower scenario optimizes

376 Toktogul releases only with respect to power generation costs in Kyrgyzstan. The Uzbek power 377 system is independent and the water allocation to agriculture in the riparian countries is determined 378 sequentially as in the basin_SSPower scenario.

$$
\mathrm{b}_{t}=-\mathbf{c}_{K Y, t p p}^{T} \cdot\left(\mathbf{t p p}_{K Y R, b a s e, t}+\mathbf{t p p}_{K Y R, p e a k, t}\right)-\mathbf{c}_{u s d}^{T} \cdot\left(\mathbf{u s d}_{K Y R, b a s e, t}+\mathbf{u s d}_{K Y R, p e a k, t}\right)
$$

\section{Scenario C: Basin_SSAgr}

381 The basin_SSAgr scenario optimizes operation of Toktogul only with respect to agricultural

382 benefits. Based on the resulting releases the power generation in Kyrgyzstan is scheduled with a 383 linear program (see Equation (2.1) considering only immediate, national power generation costs). 
384 The Uzbek power system is modeled as in the national_MS scenario. In case the power generated 385 from Toktogul releases exceeds the Kyrgyz power demand, it is assumed that Kyrgyzstan receives 386 a benefit from exporting this power at a price of $0.046 \mathrm{USD} / \mathrm{kWh}$ (Peyrouse 2009). This benefit is 387 subtracted from the thermal power production costs in Kyrgyzstan during the simulation phase. It 388 is not considered in the objective function (see Equation (2.9)).

$$
\mathrm{b}_{t}=\mathbf{m} \mathbf{b}_{a g r}^{T} \cdot \mathbf{x}_{t}
$$

390 In case the power generated from Toktogul releases is less than the Kyrgyz power demand, 391 unserved power demand costs (USD Costs) are accumulated outside of the objective function and 392 considered in the performance indicator, $P F^{\text {ind }}$, of the scenario.

\section{Scenario F: National_SSAgr}

394 The national counterpart of the basin_SSAgr scenario optimizes Toktogul releases only with 395 respect to agricultural benefits in Kyrgyzstan. However, a preliminary analysis showed that the 396 discrete inflows to Toktogul and monthly average flows from the lateral sources available to 397 FER_KYR (Src_NAR, Src_AND and Src_KAR) provide sufficient water to fully supply the 398 comparably low irrigation water demand in each month and inflow scenario. Thus, no specific 399 operation of Toktogul would be needed in this scenario and it would function as run-through 400 reservoir. In reality, it is no option to operate Toktogul as run-through reservoir and therefore this 401 scenario is not considered in the comparison. 


\section{Results and Discussion}

\section{Water Value Tables}

404 The five optimization scenarios result in steady-state water value tables which define optimal

405 reservoir operation according to the different objective functions (see Equation (2.2) and Equations

406 (2.6) to (2.9)). Contour plots of the tables are shown in Fig. 6. The tables show that the value of

407 stored water increases in each month from top to bottom of the reservoir and from the very wet to

408 the very dry inflow scenario. In months where it is important to store water for future releases the

409 water value increases compared to values in other months at the same storage level. In some water

410 value tables a drop of contour lines can be observed in June. This reflects that June is the highest

411 inflow month.

412 Almost identical water value tables are found for the national_MS and the national_SSPower

413 scenario. This emphasizes that specific operation of Toktogul is needed to satisfy Kyrgyz power

414 demand while it is not for the agricultural sector. Fig. 6 illustrates a marked increase in the cost of

415 releasing water prior to the months with highest power demand (Nov-Mar).

416 Fig. 6. Contour plots of the steady-state water value tables (water values in USD/m ${ }^{3}$ ) for the

417 basin_MS scenario (A), the basin_SSPower scenario (B), the basin_SSAgr scenario (C), the 418 national_MS scenario (D) and the national_SSPower scenario (E). The contour lines (blue lines) 419 represent reservoir levels with the same water value (number on contour line). These values 420 indicate the optimal cost for water released from the respective volume segment.

421 The water value tables of the basin_SSAgr scenario reflect the seasonality of irrigation water 422 requirements; water values are highest prior to the months with highest demand (Jun-Aug). The 423 comparably low water values indicate that, in the efficient allocation, demand satisfaction of high 
424 value crops such as fruits and vegetables does not depend on the operation of Toktogul. Water

425 supply to high demand and low value crops such as cotton seems to dominate the water value

426 tables for the basin_SSAgr scenario.

427 The water values for the basin_SSPower scenario are significantly higher than the values found

428 for the basin_SSAgr scenario indicating that hydropower production from Toktogul is more 429 valuable than releases for downstream agriculture. It turns out that the water values for this 430 scenario equal $0.0731 \mathrm{USD} / \mathrm{m}^{3}$ over large ranges of Toktogul's storage. This value corresponds to 431 the marginal power production cost of the Uzbek thermal power plants 3 and 4. Both plants have 432 large production capacities compared to more expensive power sources. It seems that hydropower 433 from Toktogul can substitute thermal power production by more expensive producers for most 434 reservoir levels in each month. However, the water values for this scenario also reveal the 435 importance of saving water for winter power demands.

436 Water values of the basin_MS scenario are the highest because the scenario considers basin-wide 437 agricultural benefits and power production costs from the joint power system between Uzbekistan 438 and Kyrgyzstan. The seasonality introduced by irrigation water demands almost disappears 439 because of joint power demands where seasonal differences are lower. From the basin perspective, 440 releases from Toktogul seem to be most valuable from December to August.

\section{Comparison of multi-sectoral cooperation scenarios}

442 The water value tables in Fig. 6 are used to simulate the operation of Toktogul for the period 1960-

443 1990. Given the scenario specific operation of Toktogul, benefits in the agricultural sector and 444 costs in the power sector are determined as described in the Materials and Method section. The 
445 performance indicator, $P F^{\text {ind }}$, was introduced which expresses the annual difference between

446 basin-wide benefits in the agricultural sector and costs in the power sector.

447

$$
\begin{aligned}
& P F_{n}^{i n d}=\sum_{t=J a n}^{D e c} \mathbf{m} \mathbf{b}_{a g r}^{T} \cdot \mathbf{x}_{t}^{*}-\mathbf{c}_{t p p}^{T} \cdot\left(\mathbf{t p p}_{\text {base }, t}^{*}+\mathbf{t p p}_{\text {peak }, t}^{*}\right)-\mathbf{c}_{u s d}^{T} \cdot\left(\mathbf{u s d}_{\text {base }, t}^{*}+\mathbf{u s d}_{\text {peak }, t}\right) \\
& \text { for } \mathrm{n}=1960,1961, \ldots, 1990
\end{aligned}
$$

448 where $\mathbf{x}_{t}^{*}, \mathbf{t p p}_{t}^{*}$ and $\mathbf{u s d}_{t}^{*}$ are basin-wide water allocation to agriculture, thermal power production

449 and unserved power demand, respectively, determined during the simulation phase for the different

450 scenarios (see Materials and Method section).

451 It should be noted that optimal operation decisions are not unique in cases where water values are

452 identical for different storage levels (see for example the basin_SSPower scenario). In these cases,

453 the simulation shows only one optimal solution for the system operation. Priority criteria could be

454 introduced to select certain candidates of the possible optimal solutions. This study did not

455 investigate this.

456 The cumulative performance indicator and national costs for the different cooperation scenarios

457 are compared. Fig. 7 shows the cumulative performance indicator for all scenarios.

458 Fig. 7. Cumulative performance indicator.

459 It can be seen that the theoretical benchmark scenario, basin_MS scenario, accumulates over the 460 simulation period at least 15 billion USD more than all remaining scenarios. This gives an estimate

461 for the potential value of international cooperation in the agricultural and the power sector. The 462 national_MS scenario accumulates at the end of the simulation period only 7 million USD more 463 than the national_SSPower scenario. It is expected from the water value tables that these two 464 scenarios result in almost identical benefits for the basin. The basin_SSAgr scenario performs 
465 worst with respect to the difference in basin-wide benefits in the agricultural sector and costs in 466 the power sector. It accumulates 1.72 billion USD less than the national_MS scenario. The 467 basin_SSPower scenario comes closest to the multi-sectoral basin cooperation benchmark. It 468 outperforms the basin_SSAgr scenario by 7.93 billion USD over the simulation period.

469 The cause of the difference in cumulative performance indicators becomes clearer when national 470 costs due to water deficits in the agricultural sector, thermal power production and unserved power 471 demand are analyzed.

472 The differences in national costs in Tajikistan and Kazakhstan are one order of magnitude lower 473 than the differences in Kyrgyzstan and Uzbekistan. This finding confirms that Toktogul's 474 operation with respect to the water use in Kyrgyzstan and Uzbekistan is key to the upstream475 downstream conflict in the Syr Darya basin from an economical perspective. Thus, the discussion 476 on national costs focuses on the differences between scenarios in Kyrgyzstan and Uzbekistan (see 477 Table 2).

478 The negative thermal production cost in Kyrgyzstan for the basin_SSAgr scenario originates from 479 Kyrgyzstan's export of excess hydropower in the summer months (see Materials and Method 480 section). While these export benefits could be lower or higher with changing export prices and 481 agreements, the values show that Kyrgyz benefits due to exported electricity are low compared to 482 differences in agricultural shortage costs in Uzbekistan and unserved power demand costs in 483 Kyrgyzstan. Therefore, it is concluded that the interpretation of the scenario comparison does not 484 depend on the value of the electricity export price. 
485 As expected, the two national scenarios succeeded to lower unserved power demand costs in 486 Kyrgyzstan significantly. This is the main reason why these two national scenarios result in 487 increased cumulative performance indicators compared to the basin_SSAgr scenario.

488 The basin_SSPower scenario creates for all countries combined less agricultural shortage costs 489 than the national_MS and the national_SSPower scenario. These two scenarios show lower 490 agricultural shortage costs only in Kyrgyzstan because substitution of some thermal power 491 production by hydropower during the vegetation period seems to be beneficial from the national 492 perspective.

493 The cumulative performance indicator of the basin_SSPower scenario is closest to the indicator of 494 the basin_MS scenario. It uses hydropower from Toktogul to keep unserved power demand costs 495 in Kyrgyzstan on a comparably low level and at the same time to lower thermal power production 496 costs in Uzbekistan. The increase of agricultural shortage costs in Uzbekistan is markedly lower 497 than saved unserved power demand costs (compare basin_SSPower and basin_SSAgr). The lower 498 value of agricultural shortage costs in Uzbekistan compared to thermal power production costs in 499 Uzbekistan and unserved power demand costs in Kyrgyzstan explains the discrepancy between the 500 basin_SSPower and basin_SSAgr scenario.

501 The basin_MS scenario allocates electricity from Uzbek thermal power production to Kyrgyzstan 502 in the winter months in order to reduce unserved power demand costs. During the vegetation 503 period, releases from Toktogul are used to limit agricultural shortage costs in all countries, reduce 504 thermal power production and unserved power demand costs in Uzbekistan. In comparison to 505 previous hydro-economic studies in the SDRB, this scenario also confirms the potential value of 506 irrigation benefits in the basin. Cai et al. (2002) and (2003) produced a benchmark for hydro- 
507 economic model results in the SDRB. In the optimized case, Cai et al. (2003) derive an annual 508 irrigation benefit of 3.26 billion USD for the entire basin. In the basin_MS scenario, the annual 509 average irrigation benefit lies in the same order of magnitude with 4.83 billion USD. The irrigation

510 benefit in this study might be different compared to Cai et al. (2003) because more crop types were 511 considered explicitly, the impact of salinity on crop yields was not considered, inflows to Toktogul 512 were described stochastically rather than assuming an average inflow year and releases for 513 hydropower are based on an endogenous hydropower value.

514 While these results illustrate potential benefits from basin cooperation similar to previous studies 515 (Arjoon et al. 2014; Teasley and McKinney 2011; Tilmant and Kinzelbach 2012; Whittington et 516 al. 2005), they also highlight obstacles to bilateral agreements. The theoretical benchmark for basin 517 cooperation in the agricultural and power sector (basin_MS scenario) generates the lowest annual 518 national costs only for Uzbekistan. Kyrgyzstan loses on average 239.7 million USD/year in the 519 basin_MS scenario compared to national appropriation of Toktogul's storage capacity 520 (national_MS scenario). Uzbekistan advocates an operation of Toktogul that satisfies the national 521 irrigation demand which would correspond to an operation similar to the basin_SSAgr scenario. 522 The comparison of national costs in the basin_SSAgr and national_MS scenario shows the 523 potential stakes of Kyrgyzstan and Uzbekistan in bilateral negotiations. Uzbekistan saves on 524 average 568 million USD/year and Kyrgyzstan loses on average 640.7 million USD/year in the 525 basin_SSAgr scenario compared to the national_MS. Together with the aversion of compensating 526 Kyrgyzstan for storing water in wet years to hedge for following dry years, these values emphasize 527 the reason for the upstream-downstream dispute on Toktogul's operation. The basin_SSPower 528 scenario seems to be a compromise between the national_MS and basin_SSAgr scenario. It lowers 529 the average annual costs for both Uzbekistan and Kyrgyzstan with respect to the national_MS and 
530 basin_SSAgr scenario, respectively. Even agricultural shortage costs in Uzbekistan are reduced in

531 the basin_SSPower scenario compared to the national_MS scenario.

532 These results are promising because cooperation in the power sector is traditionally not considered

533 by river basin commissions which focus typically on the water sector. Based on the presented case

534 study, regional power cooperation can achieve some of the benefits from multi-sectoral basin

535 cooperation in international river basins characterized by an upstream-downstream conflict on

536 water allocation to irrigated agriculture and hydropower. Nevertheless, it should be noted that the

537 benefits from the different cooperation scenarios can only ease the water-energy conflict in the

538 region if they are shared in an equitable manner.

\section{Conclusion}

540 Stochastic dynamic programming in combination with the water value method was used to derive

541 reservoir operating rules for Toktogul Reservoir under different assumptions about international

542 cooperation in both the water and energy sectors. These operating rules were then used to simulate

543 basin water use and associated economic values in order to estimate the costs and benefits of

544 different levels of cooperation. The water value method provides steady-state water value tables

545 by maximizing the sum of immediate and expected future benefits. The tables define optimal

546 reservoir releases as a function of storage level, month of the year and inflow scenario. This

547 approach is useful for defining optimal reservoir operating rules under different assumptions about

548 international cooperation, particularly when the value of inter-annual reservoir storage is key to a

549 conflict between upstream and downstream riparian states.

550 A comparison of multi-sectoral cooperation scenarios was performed to assess the impact of 551 cooperation in the power sector and the agricultural sector on basin-wide benefits. International 
552 cooperation in the power sector came closest to the multi-sectoral basin cooperation benchmark.

553 The difference of basin-wide benefits in the agricultural sector and costs in the power sector was 554510 million USD/year less than for the multi-sectoral basin cooperation scenario. International 555 cooperation in the agricultural sector alone performed by 774 million USD/year worse than the 556 basin-wide scenario for multi-sectoral cooperation. The national multi-sector and power sector 557 scenario generated almost identical benefits. Both outperformed the scenario for basin cooperation 558 in the agricultural sector by 57 million USD/year. The main cause for the scenario differences was 559 identified to be high thermal power production costs in Uzbekistan and unserved demand costs in 560 Kyrgyzstan compared to agricultural shortage costs in Uzbekistan. From a national perspective, 561 Kyrgyzstan achieved lowest annual costs in the national multi-sector scenario and Uzbekistan in 562 the basin-wide scenario for multi-sectoral cooperation followed by the scenario of international 563 cooperation in the agricultural sector. Regional power cooperation reduced national costs in 564 Kyrgyzstan compared to the basin cooperation scenarios and in Uzbekistan compared to the 565 national appropriation of Toktogul's storage capacity. Hence, regional power cooperation can 566 potentially ease international water-energy conflicts. This represents a practical alternative to the 567 traditional approach of river basin commissions which focus typically on the water sector. It is 568 essential to view power and water resources allocation jointly in international river basins where 569 the power and the agricultural sector are tightly linked by hydropower. International cooperation 570 in the power sector may ease upstream-downstream conflicts in these cases. 


\section{Acknowledgements}

572 This study was possible thanks to the data provided by the Aral Sea Basin Economic Allocation

573 Model (BEAM) project conducted by the World Bank in 2013. The authors would like to thank

574 especially Dr. Benoit Blarel for his collaboration as project coordinator of BEAM.

\section{References}

576

577

578

579

580

581

582

583

584

585

586

587

588

589

590

591

592

593

594

595

596

597

598

599

600

601

Anghileri, D., Castelletti, A., Pianosi, F., Soncini-Sessa, R., and Weber, E. (2013). “Optimizing Watershed Management by Coordinated Operation of Storing Facilities." Journal of Water Resources Planning and Management, 139(5), 492-500.

Antipova, E., Zyryanov, A., McKinney, D., and Savitsky, A. (2002). “Optimization of Syr Darya Water and Energy Uses Optimization of Syr Darya Water and Energy Uses." Water International, 27(4), 504-516.

Arjoon, D., Mohamed, Y., Goor, Q., and Tilmant, A. (2014). "Hydro-economic risk assessment in the eastern Nile River basin." Water Resources and Economics, Elsevier, 8, 16-31.

Arjoon, D., Tilmant, A., and Herrmann, M. (2016). "Sharing water and benefits in transboundary river basins." Hydrology and Earth System Sciences, 20(6), 2135-2150.

Bauer-Gottwein, P., Riegels, N., Pulido-velazquez, M., Harou, J. J., Cai, X., Davidsen, C., and Pereira-cardenal, S. J. (2016). "Chapter 36: Hydroeconomic Analysis.” Handbook of Applied Hydrology, McGraw-Hill Education, 36-1-10.

Bekchanov, M., Bhaduri, A., and Ringler, C. (2015). "Potential gains from water rights trading in the Aral Sea Basin.” Agricultural Water Management, Elsevier B.V., 152, 41-56.

Bekchanov, M., Ringler, C., Bhaduri, A., and Jeuland, M. (2016). "Optimizing irrigation efficiency improvements in the Aral Sea Basin." Water Resources and Economics, 13, 3045.

Bellman, R. (1957). Dynamic Programming. Princeton University Press, Princeton, New Jersey.

Booker, J. F., Howitt, R. E., Michelsen, A. M., and Young, R. A. (2012). "ECONOMICS AND THE MODELING OF WATER RESOURCES AND POLICIES." Natural Resource Modeling, 25(1), 168-218.

Cai, X. (1999). “A modeling framework for sustainable water resources management." The University of Texas, Austin.

Cai, X., McKinney, D. C., and Lasdon, L. S. (2002). "A framework for sustainability analysis in water resources management and application to the Syr Darya Basin." Water Resources 
Research, 38(6), 21-1-21-14.

603 Cai, X., McKinney, D. C., and Lasdon, L. S. (2003). "Integrated Hydrologic-Agronomic-

Castelletti, A., Pianosi, F., and Soncini-Sessa, R. (2008). "Water reservoir control under economic, Economic Model for River Basin Management." Journal of Water Resources Planning and Management, 129(1), 4-17.

Dinar, A., Dinar, S., McCaffrey, S., and Mckinney, D. C. (2007). "CASE STUDY 4 : THE ARAL

Dombrowsky, I. (2009). "Revisiting the potential for benefit sharing in the management of transSEA BASIN." Bridges Over Water: Understanding Transboundary Water Conflict, Negotiation and Cooperation, World Scientific Publishing Co., 125-140.

Giuliani, M., Castelletti, A., Pianosi, F., Mason, E., and Reed, P. M. (2016). "Curses , Tradeoffs , and Scalable Management: Advancing Evolutionary Multiobjective Direct Policy Search to Improve Water Reservoir Operations." Journal of Water Resources Planning and Management, 142(2), 4015050.

Harou, J. J., Pulido-Velazquez, M., Rosenberg, D. E., Medellín-Azuara, J., Lund, J. R., and Howitt, R. E. (2009). "Hydro-economic models: Concepts, design, applications, and future prospects." Journal of Hydrology, Elsevier B.V., 375(3-4), 627-643.

ICWC. (1998). Agreement Between the Governments of the Republic of Kazakhstan, the Kyrgyz Republic, and the Republic of Uzbekistan on the Use of Water and Energy Resources of the Syr Darya Basin. Bishek, The Kyrgyz Republic.

Labadie, J. W. (2004). "Optimal Operation of Multireservoir Systems: State-of-the-Art Review.” Journal of Water Resources Planning and Management, 130(2), 93-111.

Momblanch, A., Connor, J. D., Crossman, N. D., Paredes-Arquiola, J., and Andreu, J. (2016). "Using ecosystem services to represent the environment in hydro-economic models." Journal of Hydrology, Elsevier B.V., 538, 293-303.

Oberhänsli, H., Novotná, K., Píšková, A., Chabrillat, S., Nourgaliev, D. K., Kurbaniyazov, A. K., and Matys Grygar, T. (2011). "Variability in precipitation, temperature and river runoff in W Central Asia during the past 2000yrs." Global and Planetary Change, 76(1-2), 95-104.

Pereira-Cardenal, S. J., Mo, B., Riegels, N., Arnbjerg-Nielsen, K., and Bauer-Gottwein, P. (2015). "Optimization of Multipurpose Reservoir Systems Using Power Market Models." Journal of Water Resources Planning and Management, 141(8), 4014100.

Peyrouse, S. (2009). "THE CENTRAL ASIAN POWER GRID IN DANGER?" $<\mathrm{http}: / / \mathrm{www} . c a c i a n a l y s t . o r g /$ publications/analytical-articles/item/11960-analytical-articlescaci-analyst-2009-12-9-art-11960.html> (Sep. 25, 2016).

Sadoff, C. W., and Grey, D. (2002). "Beyond the river : the benefits of cooperation on international rivers." Water Policy, 4, 389-403. 
Teasley, R. L., and McKinney, D. C. (2011). "Calculating the Benefits of Transboundary River Basin Cooperation: Syr Darya Basin." Journal of Water Resources Planning and

The World Bank. (2012). Reducing the Vulnerability of Uzbekistan's Agricultural Systems to

Tilmant, A., and Kinzelbach, W. (2012). "The cost of noncooperation in international river basins." Water Resources Research, 48(1), W01503.

Tomberg, I. (2012). "Energy industry in Central Asia - challenges and prospects." $<$ http://russiancouncil.ru/en/inner/?id_4=350\#top-content> (Sep. 25, 2016).

Wangsteen, I. (2007). Power System Economics - the Nordic Electricity Market. Fagbokforlaget, Trondheim.

Whittington, D., Wu, X., and Sadoff, C. W. (2005). "Water resources management in the Nile basin: the economic value of cooperation." Water Policy, 7, 227-252.

Wolf, A. (1998). "Conflict and cooperation along international waterways." Water Policy, 1(2), 251-265.

Wolfgang, O., Haugstad, A., Mo, B., Gjelsvik, A., Wangensteen, I., and Doorman, G. (2009). "Hydro reservoir handling in Norway before and after deregulation." Energy, Elsevier Ltd, 34(10), 1642-1651.

World Energy Council. (2007). ELECTRICITY IN CENTRAL ASIA: MARKET AND INVESTMENT OPPORTUNITY REPORT. London.

$\mathrm{Wu}, \mathrm{X}$., and Whittington, D. (2006). "Incentive compatibility and conflict resolution in international river basins: A case study of the Nile Basin." Water Resources Research, 42(2), W02417. Methods. Routledge. 
669 Table 1. Summary of assumptions for different operating objectives.

\begin{tabular}{lll}
\hline \multicolumn{1}{c}{ National } & \multicolumn{1}{c}{ Basin } \\
\hline SSPower & $\begin{array}{l}\text { Toktogul's operation is optimized for } \\
\text { Kyrgyz power sector (see scenario E) }\end{array}$ & $\begin{array}{l}\text { Toktogul's operation is optimized for the } \\
\text { regional power market between Kyrgyzstan } \\
\text { and Uzbekistan. (see scenario B) }\end{array}$ \\
\hline SSAgr & $\begin{array}{l}\text { Toktogul's operation is optimized for } \\
\text { Kyrgyz agriculture sector. (see scenario F) }\end{array}$ & $\begin{array}{l}\text { Toktogul's operation is optimized for basin- } \\
\text { wide agricultural water use. (see scenario C) }\end{array}$ \\
\hline MS & $\begin{array}{l}\text { Toktogul's operation is optimized for } \\
\text { Kyrgyz agriculture and power sector (see } \\
\text { scenario D). }\end{array}$ & $\begin{array}{l}\text { Toktogul's operation is optimized considering } \\
\text { basin-wide benefits from agricultural water } \\
\text { use and costs for the regional power market } \\
\text { between Kyrgyzstan and Uzbekistan. (see } \\
\text { scenario A) }\end{array}$ \\
\hline
\end{tabular}

671 Table 2. Average annual national costs, $\left[10^{6} \mathrm{USD} / \mathrm{year}\right]$, in Kyrgyzstan and Uzbekistan due to

672 water deficits in the agricultural sector (Shortage Cost), thermal power production (TPP Cost),

673 unserved power demand (USD Cost) and both sectors combined (Total).

\begin{tabular}{lrrrrrrrr}
\hline & \multicolumn{4}{c}{ Kyrgyzstan } & \multicolumn{4}{c}{ Uzbekistan } \\
\cline { 2 - 9 } & Shortage Cost & TPP Cost & USD Cost & Total & Shortage Cost & TPP Cost & USD Cost & Total \\
\hline basin_MS & 27.1 & 41.4 & 212 & 281 & 161 & 2670 & 481 & 3312 \\
basin_SSPower & 2.54 & 41.4 & 198 & 242 & 661 & 2650 & 517 & 3828 \\
basin_SSAgr & 29.8 & -173 & 825 & 682 & 148 & 2990 & 517 & 3655 \\
national_MS & 0.0296 & 31.1 & 10.2 & 41.3 & 716 & 2990 & 517 & 4223 \\
national_SSPower & 0.218 & 31.6 & 9.6 & 41.4 & 716 & 2990 & 517 & 4223 \\
\hline
\end{tabular}




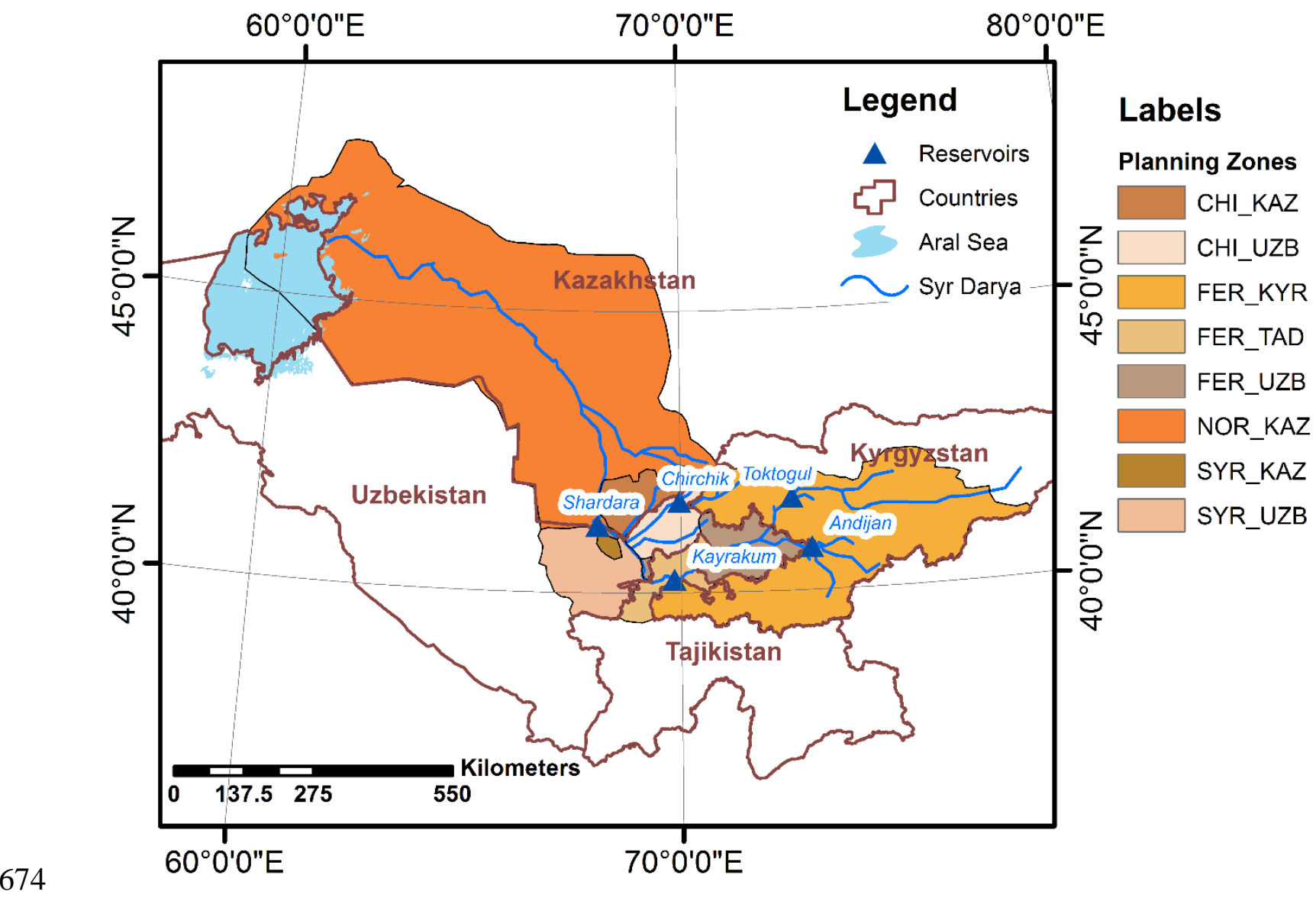

675 Fig. 1. Base Map of the Syr Darya River basin. Agricultural planning zones are introduced to

676 summarize irrigative water use in the respective area. The names of the planning zones indicate

677 the region and the country in which they are located (CHI: Chirchic River, FER: Fergana Valley,

678 NOR: Syr Darya Delta, SYR: Syr Darya Valley, KYR: Kyrgyzstan, TAD: Tajikistan, UZB:

679 Uzbekistan, KAZ: Kazakhstan). 


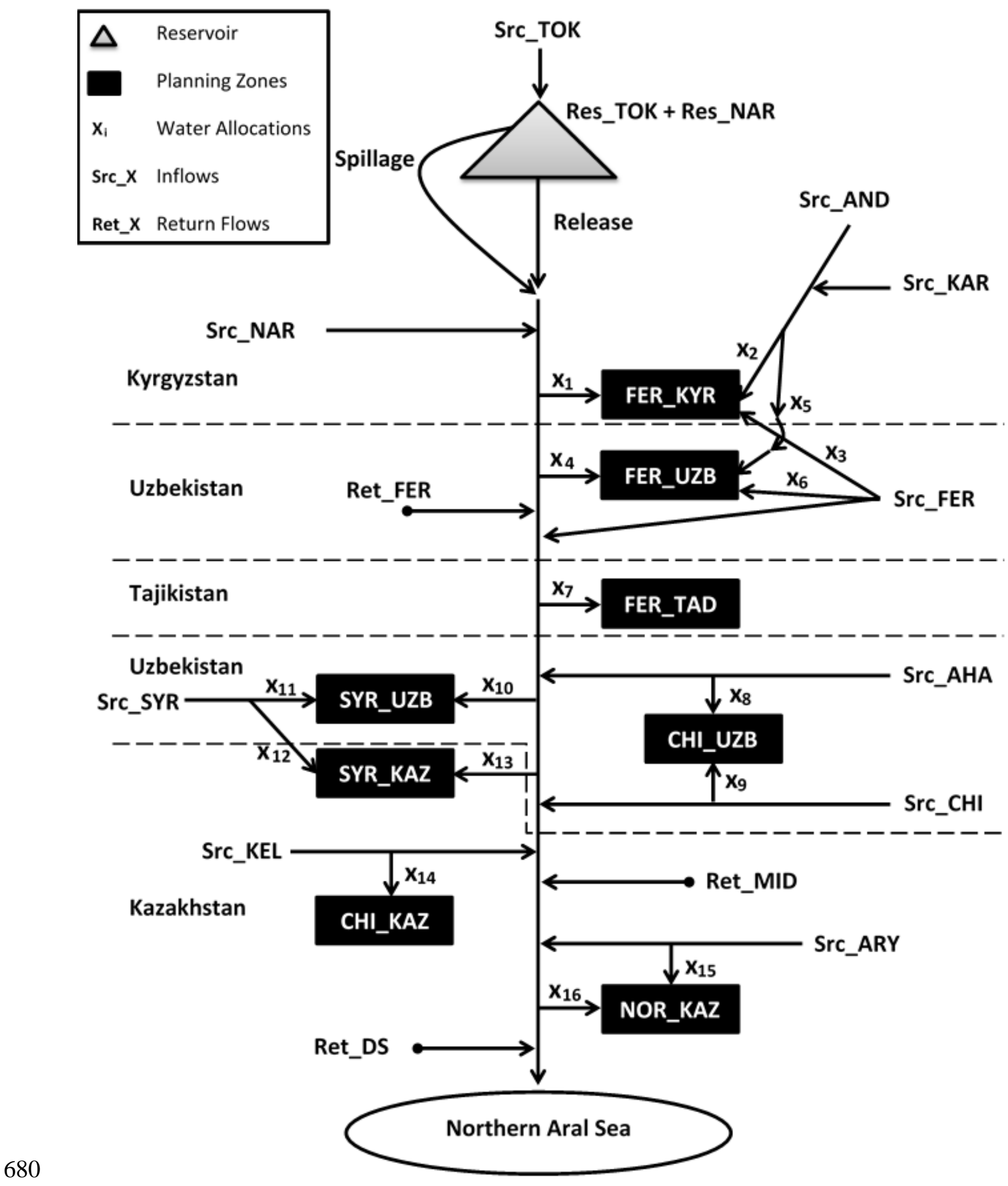

681 Fig. 2. Conceptual River Network. 


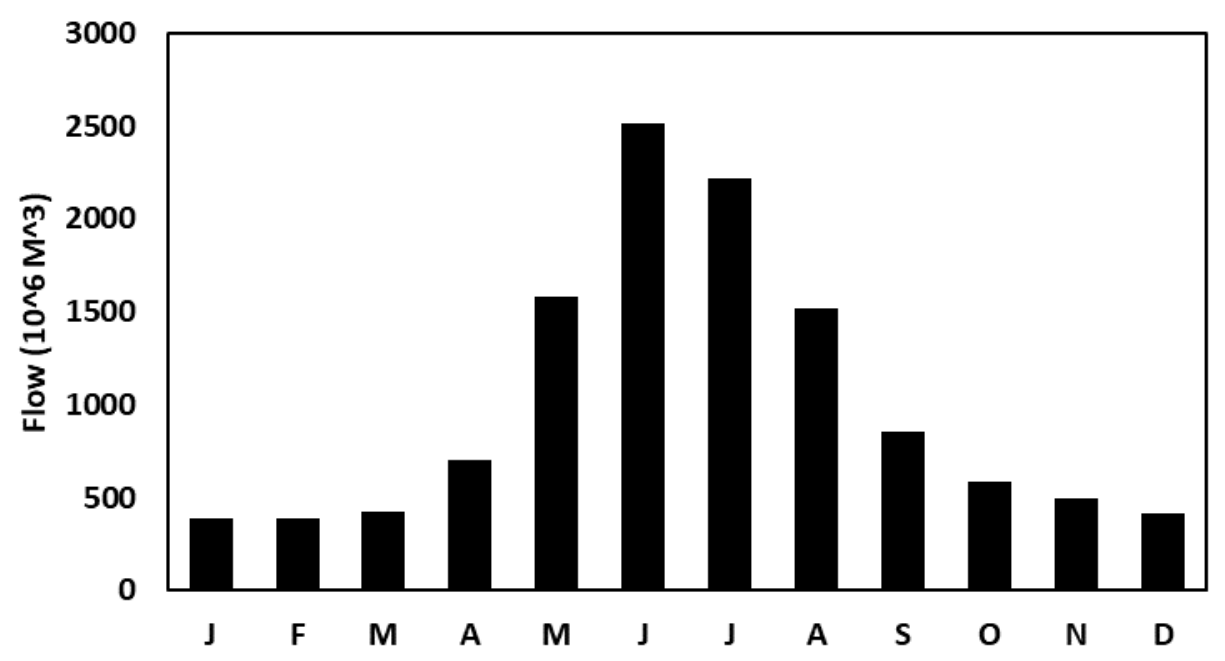

682

683 Fig. 3. Monthly average inflows to Toktogul of the period $1911-1998$.

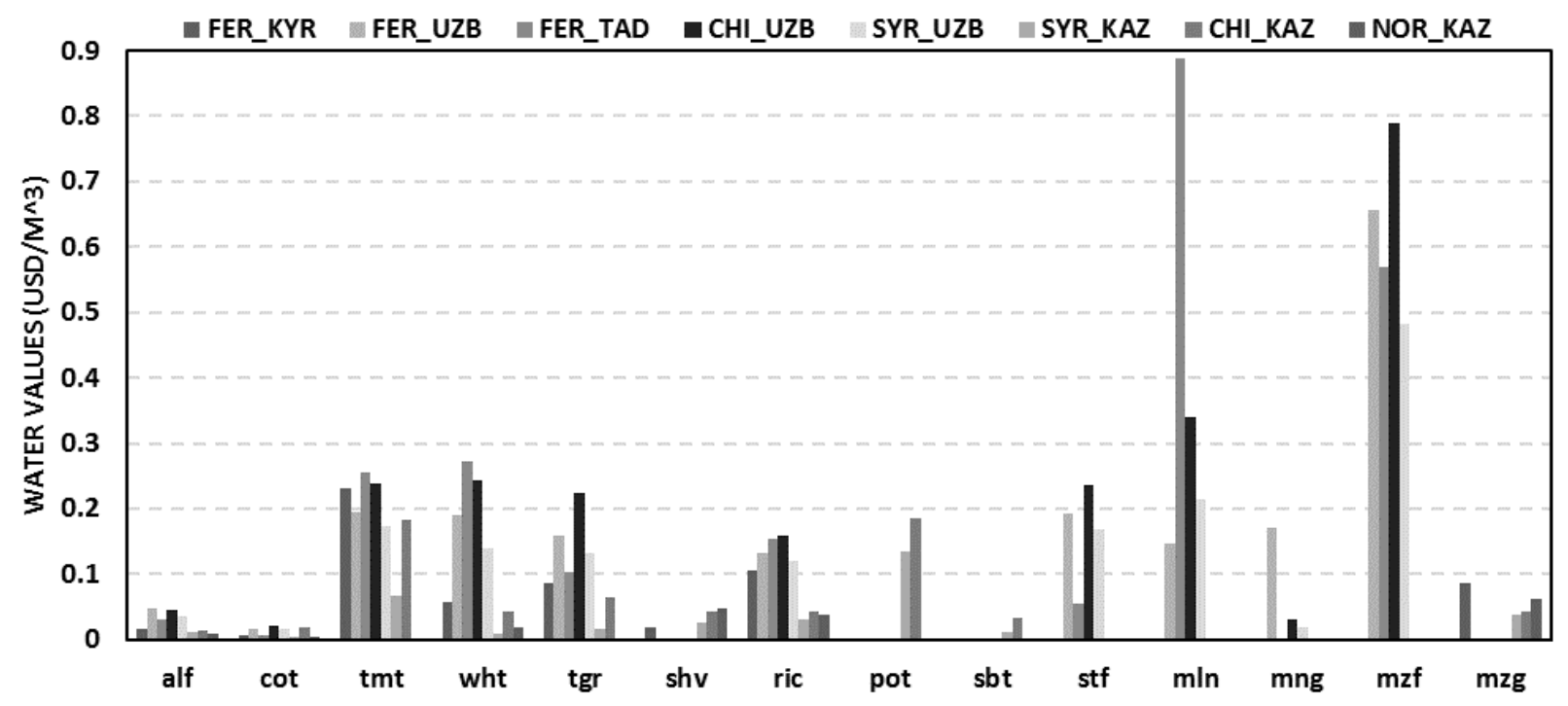

685 Fig. 4. Estimated agricultural at-source water values, (USD/m3), for each crop type and planning 686 zone in the Syr Darya basin (alf: alfalfa, cot: cotton, tmt: tomato, wht: wheat, tgr: table grapes, 687 shv: cucumber, ric: rice, pot: potato, sbt: sugar beet, stf: stone fruits, mln: melon, mng: mango, 688 mzf: maize for fodder, mzg: maize for grain). It should be noted that cotton is among the low value 689 crops. 


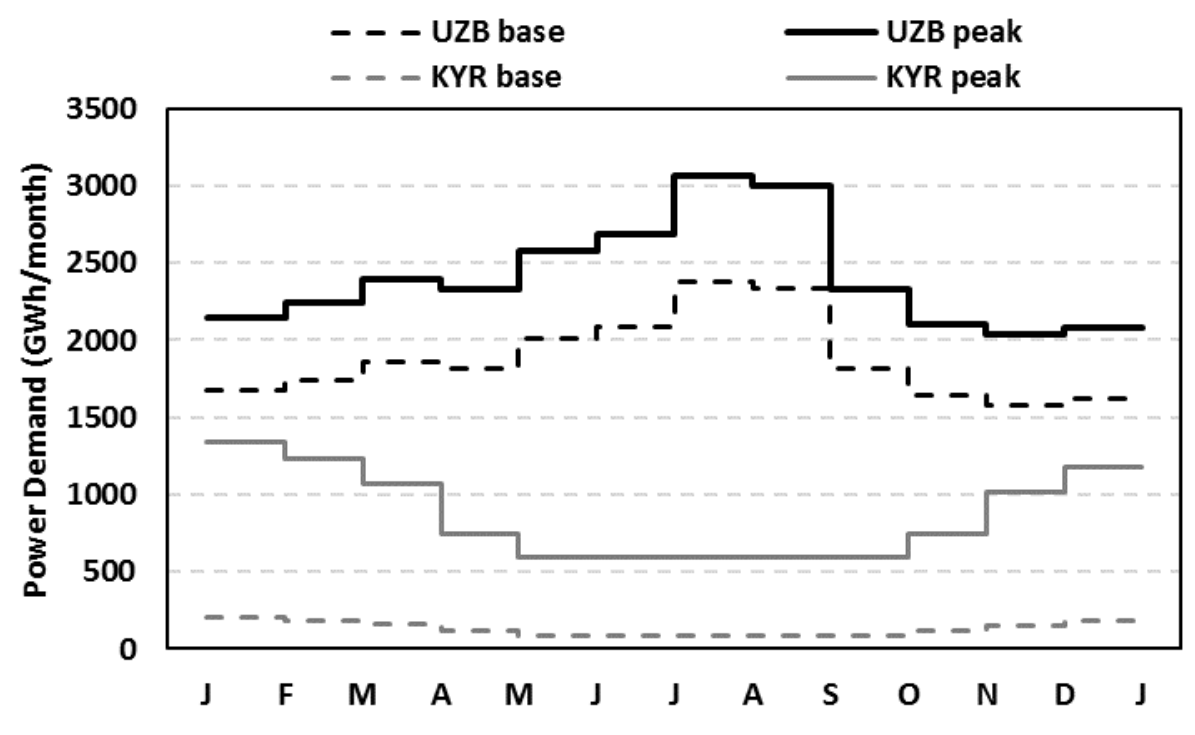

691 Fig. 5. Observed monthly power demand in Uzbekistan and Kyrgyzstan during base and peak 692 hours, (GWh/month). 


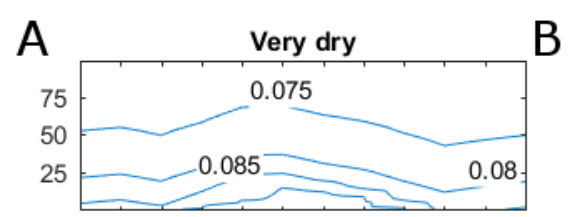

Dry
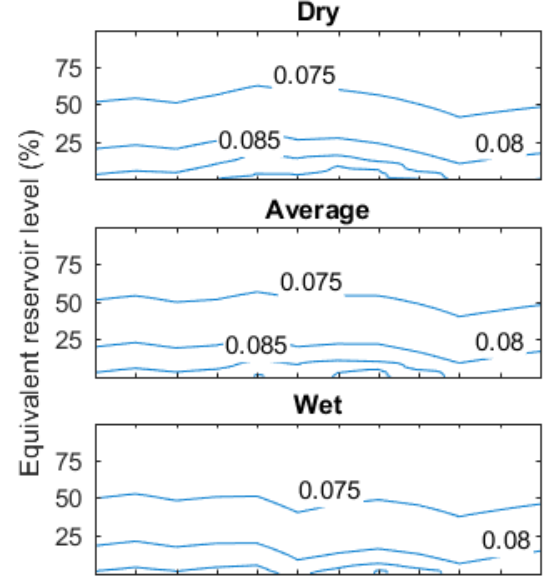

Very wet
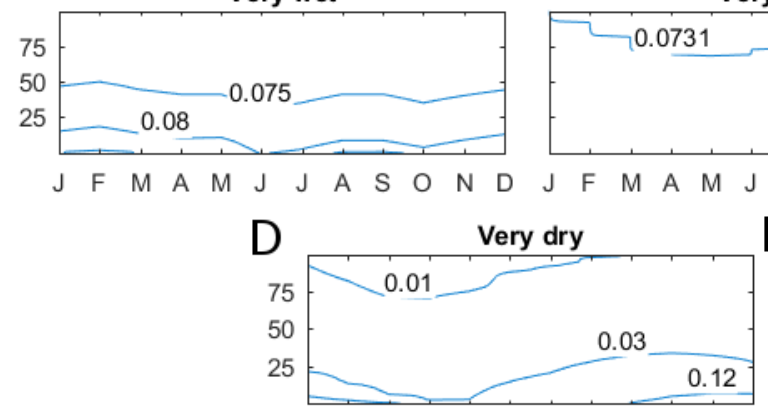

Dry
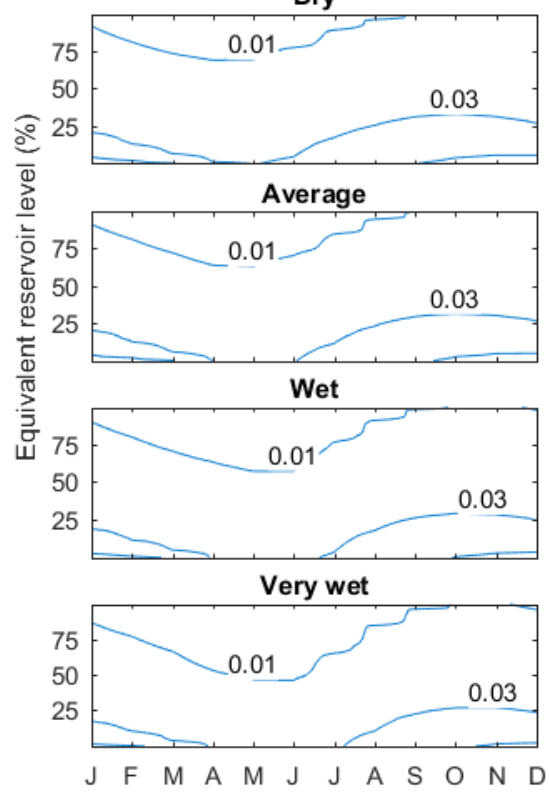

Dry

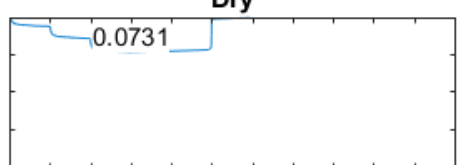

Average

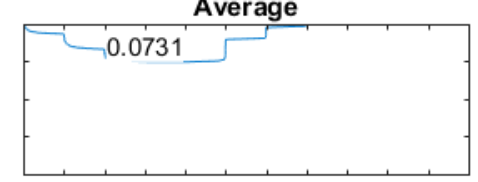

Wet

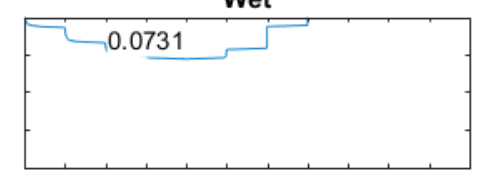

Very wet

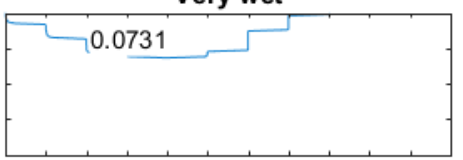

C

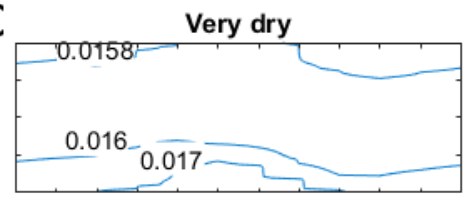

Dry

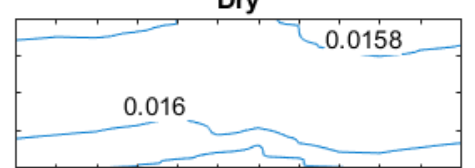

Average

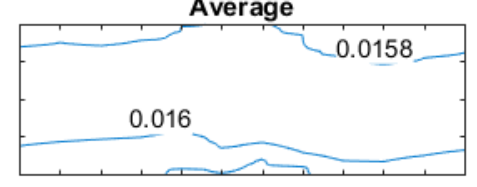

Wet

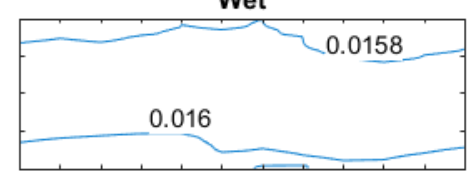

Very wet

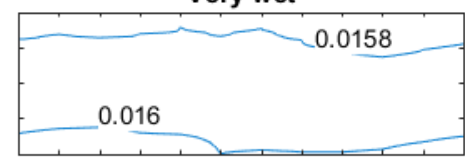

E

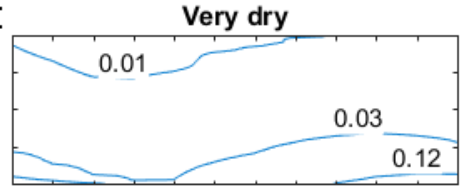

Dry

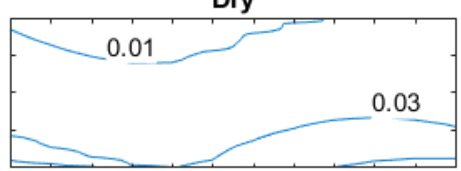

Average
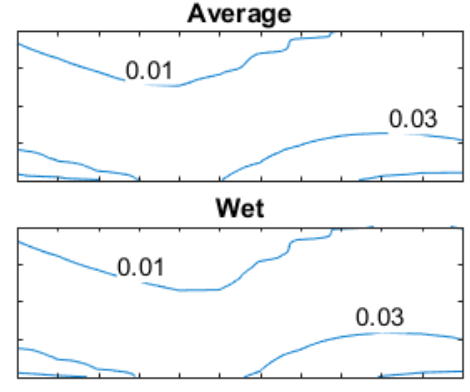

Very wet

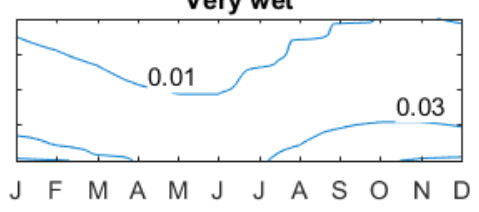


694 Fig. 6. Contour plots of the steady-state water value tables (water values in USD/m ${ }^{3}$ ) for the 695 basin_MS scenario (A), the basin_SSPower scenario (B), the basin_SSAgr scenario (C), the 696 national_MS scenario (D) and the national_SSPower scenario (E). The contour lines (blue lines)

697 represent reservoir levels with the same water value (number on contour line). These values 698 indicate the optimal cost for water released from the respective volume segment.

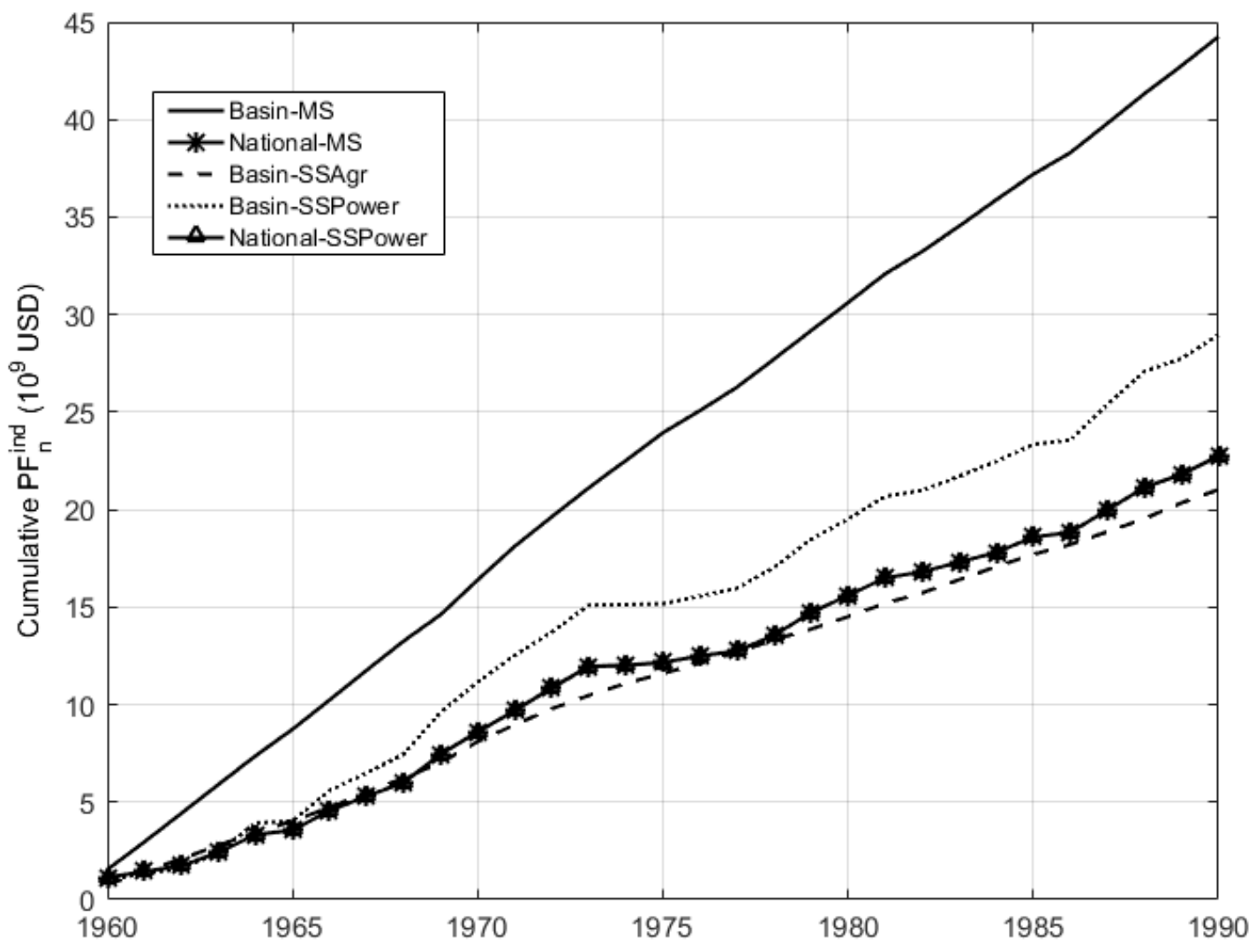

699

Fig. 7. Cumulative performance indicator. 